\title{
The relationship of urinary albumin excretion rate to ambulatory blood pressure and erythrocyte sodium-lithium countertransport in NIDDM
}

\author{
J.H.Pinkney ${ }^{1}$, W.-J.Foyle ${ }^{1}$, A. E.Denver ${ }^{1}$, V.Mohamed-Ali ${ }^{1}$, S. McKinlay ${ }^{2}$, J. S. Yudkin ${ }^{1}$ \\ ${ }^{1}$ Department of Medicine, University College London School of Medicine, Whittington Hospital, London, UK \\ ${ }^{2}$ Department of Cardiology, National Heart and Lung Institute, London, UK
}

Summary Increased erythrocyte sodium-lithium countertransport rate is found in non-diabetic subjects with essential hypertension, and in insulin-dependent diabetic subjects with nephropathy. However, relationships between these variables in non-insulin-dependent diabetic subjects are ill-defined. In order to characterise the relationships between blood pressure, urinary albumin excretion, and erythrocyte sodium-lithium countertransport, 66 subjects with non-insulin-dependent diabetes were studied. Urinary albumin excretion rate correlated with mean 24$\mathrm{h}$ ambulatory systolic blood pressure $(r=0.57 ; p<$ 0.001 ), but not with sodium-lithium countertransport $(r=0.06 ; p=0.31)$. No significant relationship was observed between 24 -h systolic blood pressure and erythrocyte sodium-lithium countertransport $(r=$ $0.16 ; p=0.17)$. The principal differences between microalbuminuric and normoalbuminuric subjects (albumin excretion rate $>15 \mu \mathrm{g} \cdot \min ^{-1}[n=20]$, and $\left.<15 \mu \mathrm{g} \cdot \mathrm{min}^{-1},[n=46]\right)$ were: higher 24 -h systolic blood pressure $(145.9$ [16.8] $\mathrm{mmHg}$ vs 131.9 [16.8] $\mathrm{mm} \mathrm{Hg} ; p=0.006)$, nocturnal heart rate $(72.4$ [8.9] vs 67.4 [8.9] beats $\cdot \min ^{-1} ; p=0.042$ ), and $\mathrm{HbA}_{1}$
(11.3 [1.5] \% vs $10.1[2.0] \% ; p=0.028)$, and a longer median duration of diabetes (10.0 vs 5.0 years; $p=$ 0.02 ). In contrast, there was no significant difference in sodium-lithium countertransport rate between microalbuminuric $\left(0.41[0.18] \mathrm{mmol} \cdot \mathrm{l}^{-1} \cdot \mathrm{h}^{-1}\right)$ and normoalbuminuric subjects $\left(0.39[0.15] \mathrm{mmol} \cdot 1^{-1}\right.$. $\left.\mathrm{h}^{-1} ; p=0.687\right)$. In multiple regression analysis controlling for race, age, body mass index and $\mathrm{HbA}_{1}$, the significant determinants of albumin excretion rate were 24 -h systolic blood pressure (B [regression coefficient $]=0.029, \mathrm{SE}[\mathrm{B}] \quad$ [standard error of $\mathrm{B}]=0.009, t=2.95, p=0.005$ ), duration of diabetes $(\mathrm{B}=0.430, \mathrm{SE}[\mathrm{B}]=0.169, t=2.54, p=0.016)$ and male gender $(\mathrm{B}=-1.170, \mathrm{SE}[\mathrm{B}]=0.457, \mathrm{t}=-2.56$, $p=0.015$ ). In conclusion, albumin excretion rates in non-insulin-dependent diabetic subjects are linked to hypertension and glycaemic exposure, but show no relationship to erythrocyte sodium-lithium countertransport. [Diabetologia (1995) 38: 356-362]

Key words Non-insulin-dependent diabetes, microalbuminuria, hypertension, sodium-lithium countertransport.
Received: 30 May 1994 and in revised form: 9 September 1994

Corresponding author: Dr. J.Pinkney, Department of Medicine, U. C. L. School of Medicine, Whittington Hospital, Archway Wing, G-Block, Archway Road, London N19 3UA, UK Abbreviations: IDDM, Insulin-dependent diabetes mellitus; NIDDM, non-insulin dependent diabetes mellitus; SLC, sodium lithium countertransport; AER, albumin excretion rate; $B$, regression; SE, coefficient; standard error of $B$.
The term microalbuminuria has been applied to a urinary albumin excretion rate (AER) of $20-200 \mu \mathrm{g}$. min $^{-1}$, undetectable using conventional strip testing methods, but predicting the development of subsequent dipstick-positive proteinuria $[1,2]$. In non-insulin-dependent diabetes mellitus (NIDDM), microalbuminuria is a stronger predictor of premature mortality from cardiovascular disease [3-5], than from nephropathy.

Increased erythrocyte sodium-lithium countertransport (SLC) is a characteristic of essential hypertension [6], and is found in nephropathic insulin-de- 
pendent diabetic (IDDM) subjects [7,8]. The finding of an increased prevalence of essential hypertension in relatives of IDDM subjects with nephropathy [9], together with the familial aggregation of SLC characteristics $[8,10]$, could suggest that elevated SLC is genetically determined, and carries an inherited predisposition to essential hypertension and diabetic nephropathy. This could explain the observation that only around one-third of subjects with IDDM eventually develop nephropathy [11].

The relationships between SLC, blood pressure, and proteinuria in NIDDM are less clear. Nephropathy in NIDDM may be associated with an increased prevalence of hypertension and increased erythrocyte SLC and platelet sodium-hydrogen exchange [12]. However, Trevisan et al. [13] found no difference in SLC between uncomplicated NIDDM and control subjects. Gall et al. [14] found no difference between NIDDM subjects with and without proteinuria, and no difference between diabetic and nondiabetic control subjects. Johnson et al. [15] found that black hypertensive NIDDM subjects had higher SLC than normotensive NIDDM control subjects. It is uncertain whether such divergent results stem from different methodologies, or from factors such as the composition and size of the groups studied. A further difficulty in studying relationships between hypertension and other variables is the physiological variation of blood pressure, creating difficulties in establishing a reliable classification of subjects. Therefore, we performed a study to investigate the relationships between AER, ambulatory blood pressure, and erythrocyte SLC in non-proteinuric subjects with NIDDM, in order to test the hypothesis that any association between AER and hypertension might be explicable in terms of levels of erythrocyte SLC.

\section{Subjects and methods}

Subjects. The study was approved by the District Ethical Committee. We recruited 66 subjects with NIDDM from the diabetic clinic who subsequently gave their written informed consent. The inclusion criteria were a known diabetes duration of at least 12 months, age at onset of diabetes 35 years or over, no use of insulin in the first year after diagnosis, no history of ketoacidosis, and current treatment with either diet, oral hypoglycaemic agents, or insulin. Urinary tract infections were excluded by urine microscopy and culture. Patients with dipstick positive proteinuria, haematuria, or serum creatinine greater than $200 \mu \mathrm{mol} \cdot \mathrm{l}^{-1}$, were excluded, as were those with other renal diseases, clinical evidence of cardiopulmonary or hepatic disease, secondary hypertension, a history of alcohol abuse, and subjects receiving any drugs affecting blood pressure or renal function. Subjects with treated essential hypertension were included after a treatment wash-out period of 4 weeks. Hypertension was defined as a mean of three casual diastolic blood pressure measurements greater than $95 \mathrm{~mm} \mathrm{Hg}$ while off treatment, using a mercury sphygmomanometer. By this definition, 30 subjects were hypertensive and 36 were normotensive.
Subjects attended the clinic between 08.00 and 09.00 hours after fasting overnight, and not having taken diabetic medication on the morning of the investigations. Casual blood pressure was recorded with a mercury sphygmomanometer, after sitting for $5 \mathrm{~min}$. Subjects were weighed in light clothing, and height was recorded without shoes. Body mass index (BMI) was calculated as weight $\cdot$ height $^{-2}$. Waist circumference was taken at the level of the umbilicus and hip circumference at the level of the greater trochanters using a steel tape, and measurements were made in triplicate. The waist : hip ratio was calculated. After $15 \mathrm{~min}$ resting, blood was drawn for assay of erythrocyte SLC. Ambulatory blood pressure monitors were fitted, and subjects provided with containers and instructions for a concurrent timed overnight collection of urine $(22.00-$ 08.00 hours).

Ambulatory blood pressure monitoring. Ambulatory blood pressure was measured with a Takeda TM 2420 auscultatory monitor (A \& D Instruments, Tokyo, Japan.), fitted to the non-dominant arm. Ambulatory blood pressure profiles were recorded for a period of $24 \mathrm{~h}$. Measurements were taken every $15 \mathrm{~min}$ during the day (07.00 to 23.00 hours) and every $30 \mathrm{~min}$ overnight. Subjects previously receiving antihypertensive agents remained off treatment until the blood pressure recording and urine collection were complete. Subjects recorded the times of waking and sleeping and other activities in a diary. Blood pressure records less than $80 \%$ complete were repeated. Data were analysed on a desktop computer. In the analysis, all data points were included, but any missing observation times were deleted before calculation of mean daytime and nighttime values, according to patients' diaries.

Assay methods. Erythrocyte SLC was assayed according to the method of Canessa ef al. [6], with the modification adopted both by Mangili et al. [7] and by Foyle and Drury [16]. The within-assay and between-assay coefficients of variation for this assay were $9.5 \%$ and $13 \%$, respectively. Urinary albumin was assayed by an in-house modification of an ELISA technique [17]. Glycated haemoglobin $\left(\mathrm{HbA}_{1}\right)$ was measured by electroendosmosis (Ciba-Corning, Halstead, Essex, UK). Insulin was assayed by specific two-site immunoenzymometric assay [18], based on the two-site monoclonal assay described by Sobey et al. [19]. Plasma glucose was measured by the glucose oxidase method (Beckman, Brea, Calif., USA). Serum lipids were determined by enzymatic colorimetric methods (total cholesterol, Boehringer Mannheim, Lewes, Sussex, UK; total triglycerides, Roche Diagnostics, Welwyn Garden City, Herts, UK). HDL cholesterol was measured by the same method after the precipitation of LDL with phosphotungstic acid in the presence of magnesium ions.

\section{Statistical analysis}

Relationships between AER, blood pressure, and SLC were examined in all 66 subjects. Subjects were then divided into normoalbuminuric and microalbuminuric groups, with a cutoff at $15 \mu \mathrm{g} \cdot \mathrm{min}^{-1}$ (normoalbuminuric subjects $<15 \mu \mathrm{g}$. $\min ^{-1}, \quad n=46 ; \quad$ microalbuminuric subjects $>15 \mu \mathrm{g} \cdot \mathrm{min}^{-1}$, $n=20$ ). With these numbers of subjects, the study had over $80 \%$ power to demonstrate both a $10 \%$ difference in 24 -h ambulatory systolic blood pressure, and a $25 \%$ difference in SLC, between the normoalbuminuric and microalbuminuric groups, at the $5 \%$ level. Statistical analysis was performed with Statistical Package for the Social Sciences (SPSS-PC). All data distributions were inspected. Skewed data were logarithmically transformed, and reinspected to confirm normality. In instances where lesser degrees of positive skewness could be reduced by logarithmic transformation, this was done. All sub- 
Table 1. Characteristics of the 66 subjects with NIDDM

\begin{tabular}{ll}
\hline Age (years) & $55.9[7.6]$ \\
Sex $($ male $:$ female) & $51: 15$ \\
Race $(\mathrm{C}, \mathrm{AC}, \mathrm{A})^{\mathrm{a}}$ & $43,12,11$ \\
Waist: hip ratio & $0.92[0.07]$ \\
BMI $\left(\mathrm{kg} \cdot \mathrm{m}^{-2}\right)$ & $28.0[4.78]$ \\
Diabetes duration (years) & $5.0[1.0-26.0]$ \\
Glycated $\mathrm{Hb} \mathrm{A}_{1}(\%)$ & $10.5[1.9]$ \\
Albumin excretion rate $\left(\mu \mathrm{g} \cdot \mathrm{min}^{-1}\right)$ & $8.2[0.2-180.6]$ \\
$\mathrm{Na} / \mathrm{Li}$ countertransport $\left(\mathrm{mmol} \cdot^{-1} \cdot \mathrm{h}^{-1}\right)$ & $0.397[0.156]$ \\
\hline a C, Caucasian; AC, Afro-Caribbean; A, Asian \\
Data are given as mean [SD], or as median [range] for skewed \\
data
\end{tabular}

Table 2. Relationships of indices of 24-h ambulatory blood pressure and heart rate, and clinic blood pressure measurements, to AER, and erythrocyte sodium-lithium countertransport in 66 subjects with NIDDM

\begin{tabular}{lll}
\hline Index of blood pressure & $\begin{array}{l}\text { correlation } \\
(r) \text { with AER } \\
\text { p-value }\end{array}$ & $\begin{array}{l}\text { correlation } \\
(r) \text { with Na/Li CT } \\
\text { p-value }\end{array}$ \\
\hline 24-h mean systolic & $0.57<0.001$ & $0.16=0.165$ \\
24-h mean diastolic & $0.41<0.001$ & $0.19=0.064$ \\
Daytime mean systolic & $0.58<0.001$ & $0.15=0.130$ \\
Daytime mean diastolic & $0.41<0.001$ & $0.22=0.048$ \\
Nighttime mean systolic & $0.40<0.001$ & $0.05=0.336$ \\
Nighttime mean diastolic & $0.27=0.019$ & $0.04=0.375$ \\
Clinic systolic & $0.52<0.001$ & $0.19=0.067$ \\
Clinic diastolic & $0.52<0.001$ & $0.19=0.074$ \\
Daytime heart rate & $0.24=0.031$ & $0.20=0.058$ \\
Nighttime heart rate & $0.39=0.001$ & $0.10=0.224$ \\
Mean 24-h heart rate & $0.28=0.013$ & $0.18=0.075$ \\
\hline
\end{tabular}

sequent analyses were performed with parametric methods. Between-variable relationships were analysed with linear regression analysis. Differences between normoalbuminuric and microalbuminuric subjects were examined with Student's $t$ test and two-tailed $p$ values are given. The relationships between microalbuminuria and the categorical variables of gender and race, were examined with chi-square or Fisher's Exact Tests. With AER as the dependent variable, the interrelationship between blood pressure indices and other predictor variables was examined by multiple linear regression analyses.

\section{Results}

Characteristics of the subjects are shown in Table 1 . All subjects were included in the analysis on the basis of negative tests for proteinuria with conventional dipsticks and AER less than $200 \mu \mathrm{g} \cdot \mathrm{min}^{-1}$. Microalbuminuria was then defined as AER greater than $15 \mu \mathrm{g} \cdot \mathrm{min}^{-1}$.

The relationships between AER, SLC, and indices of blood pressure are shown in Table 2. For the whole group, mean ambulatory daytime and 24-h systolic blood pressure correlated best with AER $(r=0.58$ and $0.57 ; p<0.001$ ). The relationship between mean 24-h ambulatory systolic blood pressure and AER is

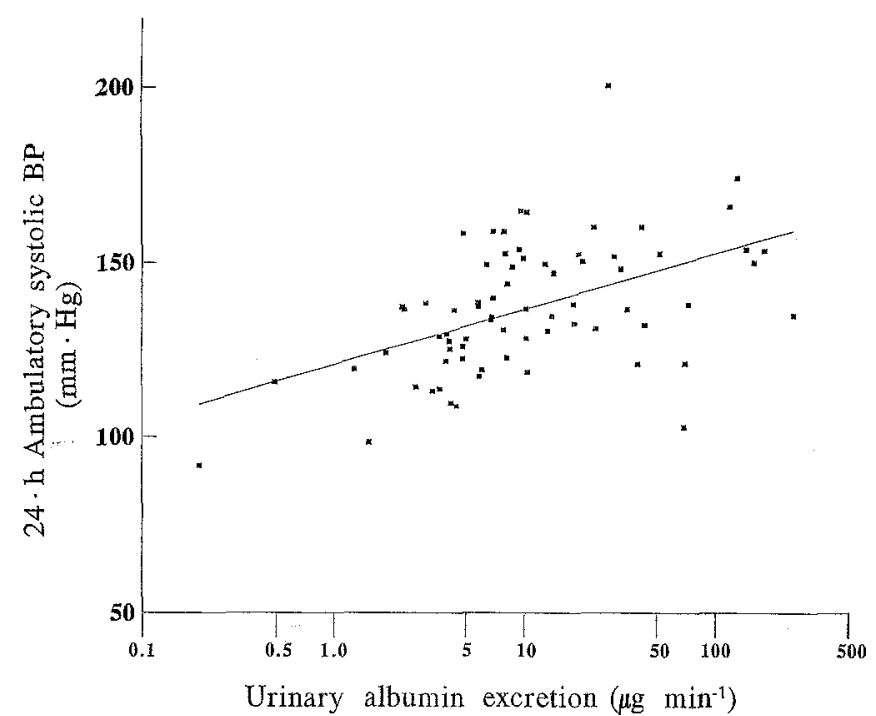

Fig. 1. Relationship between $24-\mathrm{h}$ mean ambulatory systolic blood pressure and urinary albumin excretion rate in $66 \mathrm{sub}$ jects with NIDDM. $r=0.57 ; p<0.001$

shown in Figure 1. Correlations between clinic blood pressure and AER were similar to those obtained by ambulatory monitoring, showing the accuracy of careful casual readings, although the absolute values of clinic readings were higher. All blood pressure indices examined correlated closely with AER, whereas the relationship with SLC was far weaker. The mean heart rate, particularly at night, correlated with AER, but not with SLC. In contrast to the relationships between AER and blood pressure, there was no relationship between AER and SLC $(r=0.06 ; r=0.31)$.

Subjects were divided into two groups of 46 normoalbuminuric $\left(\mathrm{AER}>15 \mu \mathrm{g} \cdot \mathrm{min}^{-1}\right)$ and 20 microalbuminuric subjects (AER $>15 \mu \mathrm{g} \cdot \mathrm{min}^{-1}$ ). Table 3 summarises blood pressure, SLC, and other descriptive and biochemical data according to albuminuria status. Eighteen of the 20 subjects with microalbuminuria were male, as opposed to 33 out of 46 of the normoalbuminuric subjects $(p=\mathrm{NS})$. The microalbuminuric group was composed of 10 Caucasians (Europids), 5 Afro-Caribbeans, and 5 Indian Asians, and the normoalbuminuric group was composed of 33 Caucasians, 7 Afro-Caribbeans, and 6 Indian Asians ( $p=\mathrm{NS}$ ). There were no significant differences between the groups in terms of age, obesity, SLC, concentrations of total serum cholesterol, HDL-cholesterol, triglycerides, fasting serum insulin or glucose. However, microalbuminuric subjects had higher mean $\mathrm{HbA}_{1}$ compared with the normoalbuminuric group, and a longer known duration of diabetes.

Because SLC was significantly higher in Caucasians compared with Afro-Caribbeans (0.42 [0.17] vs 0.33 [0.14]; $p=0.02$ ), we analysed the data in the largest single ethnic group, namely 43 Caucasians. In this 
Table 3. Clinical characteristics, biochemistry, and erythrocyte sodium-lithium countertransport in 46 NIDDM subjects with normal urinary albumin excretion and 20 with microalbuminuria

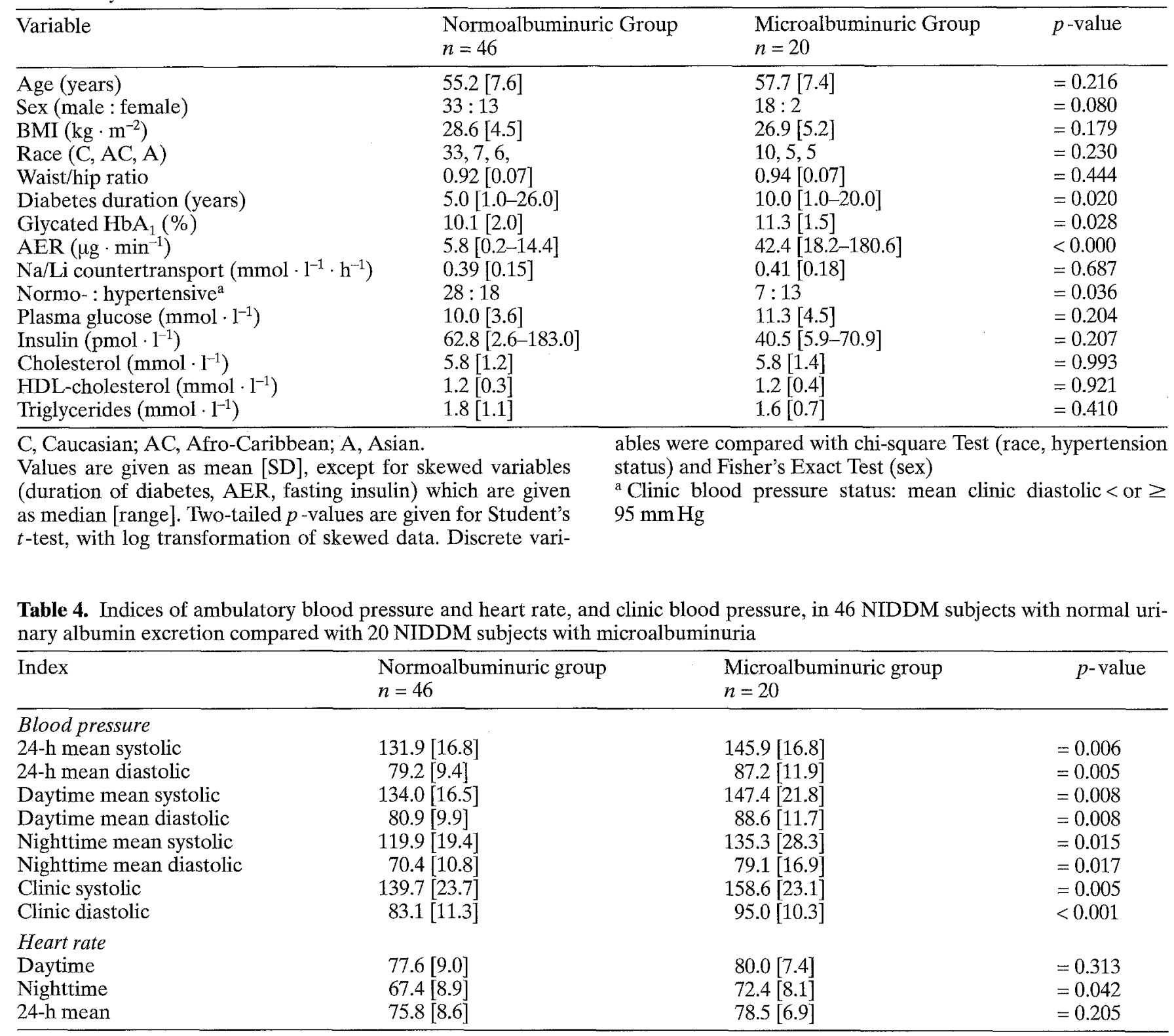

Values are given as mean [SD] $\mathrm{mm} \mathrm{Hg}$, with two-tailed $p$-values for Student's $t$-test

group AER was still closely related to 24-h systolic blood pressure $(r=0.48, p<0.001)$ but not to SLC $(r=0.02, p=\mathrm{NS})$.

Mean (SD) 24-h and daytime systolic and diastolic blood pressures were higher in the microalbuminuric group (Table 4) and there were smaller differences in mean nocturnal blood pressures. Clinic blood pressures exceeded daytime ambulatory pressures, but also differentiated the normo- and microalbuminuric groups. The nocturnal dips in both systolic and diastolic blood pressure were not significantly different between the normo- and microalbuminuric groups. However, the nocturnal pulse rate was higher in microalbuminuric than in normoalbuminuric subjects.
In order to test whether the cut-off point used to define microalbuminuria influenced the outcome of the present study, the data analyses were repeated, defining microalbuminuria as AER greater than $10 \mu \mathrm{g} \cdot \mathrm{min}^{-1}$, and AER greater than $20 \mu \mathrm{g} \cdot \min ^{-1}$. Comparisons between the micro- and normoalbuminuric groups, based on these definitions (summarised in Table 5), showed the same pattern of relationships between AER, blood pressure, and SLC, as was found when microalbuminuria was defined as AER greater than $15 \mu \mathrm{g} \cdot \mathrm{min}^{-1}$. Similarly, taking an upper AER limit of 150 rather than $200 \mu \mathrm{g} \cdot \mathrm{min}^{-1}$ to define microalbuminuria only two subjects were excluded from the analysis, without any significant effect on any of the relationships observed. 
Table 5. Comparisons of 24-h ambulatory blood pressure and sodium-lithium countertransport between the normoalbuminuric and microalbuminuric groups using different thresholds of AER as the cut-off points to define microalbuminuria

\begin{tabular}{llll}
\hline $\begin{array}{l}\text { Cut-off point } \\
{\left[\mu \mathrm{g} \cdot \mathrm{min}^{-1}\right]}\end{array}$ & $\begin{array}{l}\text { Subject numbers } \\
\text { Normo : Micro }\end{array}$ & $\begin{array}{l}\text { Mean }[\mathrm{SD}] 24-\mathrm{h} \text { systolic blood } \\
\text { pressures }(\mathrm{mmHg} \text { in normo- } \\
\text { and microalbuminuric groups }\end{array}$ & $\begin{array}{l}\text { Means [SD] sodium-lithium counter- } \\
\text { transport }\left(\mathrm{mmol} \cdot \mathrm{l}^{-1} \cdot \mathrm{h}^{-1}\right) \text { in normo- } \\
\text { and microalbuminuric groups }\end{array}$ \\
\hline 10.0 & $38: 28$ & $130.5[17.1]: 143.9[19.5]$ & $0.385[0.142]: 0.414[0.175]$ \\
& & $t=2.97, p=0.004$ & $t=0.73, p=0.469$ \\
15.0 & $46: 20$ & $131.9[16.8]: 145.9[21.2]$ & $0.392[0.146]: 0.409[0.181]$ \\
& & $t=2.87, p=0.006$ & $t=0.41, p=0.687$ \\
20.0 & $49: 17$ & $132.5[16.6]: 146.8[22.7]$ & $0.400[0.153]: 0.389[0.170]$ \\
& & $t=2.77, p=0.007$ & $t=0.27, p=0.788$ \\
\hline
\end{tabular}

Test statistic $(t)$ and two-tailed $p$-value are given for Student's $t$-test

Table 6. Independent contributions of variables in a multiple regression model of the determinants of AER in 66 non-proteinuric NIDDM subjects

\begin{tabular}{lccll}
\hline Predictor variable & $\mathrm{B}$ & $\mathrm{SE}[\mathrm{B}]$ & $\mathrm{t}$ & $\mathrm{P}$ \\
\cline { 1 - 4 } Sex & -1.170 & 0.457 & -2.56 & 0.015 \\
Diabetes duration & 0.430 & 0.169 & 2.535 & 0.016 \\
HbA $_{1}$ & 0.170 & 0.087 & 1.953 & 0.058 \\
24-h ASBP & 0.029 & 0.009 & 2.953 & 0.005 \\
$\begin{array}{l}\text { Na/Li counter- } \\
\text { transport }\end{array}$ & 0.319 & 1.200 & 0.266 & 0.792 \\
\hline
\end{tabular}

24-h ASBP, 24-h ambulatory systolic blood pressure

A multiple linear regression analysis was performed for the whole group, in order to explore the relationships between blood pressure, duration of diabetes, glycaemic control, SLC, and AER. In this model $\left(R^{2}=0.48, F=5.04, p=0.0002\right)$, with AER as the dependent variable, and controlling for race, age and BMI, AER was predicted by male sex, increasing duration of diabetes, and higher 24-h mean ambulatory systolic blood pressure. $\mathrm{HbA}_{1}$ levels were of borderline significance. In contrast, SLC was not significantly related to AER (Table 6).

\section{Discussion}

We have demonstrated a close association between blood pressure and AER in subjects with NIDDM. In contrast, blood pressure was generally unrelated to SLC, and there was no relationship between SLC and AER. Microalbuminuria was also associated with a longer duration of diabetes, higher current levels of $\mathrm{HbA}_{1}$, and male gender.

There have been few previous studies of SLC in subjects with NIDDM. Trevisan et al. [13] found no difference in SLC between groups of 22 hypertensive and 22 normotensive NIDDM subjects. It is possible, however, that the hypertension classification used in this study, which was treatment with antihypertensive drugs, or systolic or diastolic blood pressures over 140 and $90 \mathrm{~mm} \mathrm{Hg}$, was too imprecise. The study of Gall et al. [14] suggested that subjects with NIDDM had higher SLC rates than non-diabetic control subjects, but that nephropathic subjects had no further elevation compared with normoalbuminuric NIDDM subjects. Importantly, the nephropathic and normoalbuminuric groups differed significantly in blood pressure. Although these studies failed to detect any increase in SLC in hypertensive NIDDM subjects, other studies [15] have suggested a relationship between blood pressure and SLC. Thus, increased SLC may be associated with hypertension in NIDDM, as in non-diabetic subjects, although the relationship appears not to be strong. In our study, the lack of relationship between SLC and AER in the microalbuminuric range suggests that increased SLC is not likely to be an initiating factor in the development of nephropathy. In view of the smaller numbers of subjects at higher levels of microalbuminuria, and the absence of a comparison group of patients with dipstick-positive proteinuria, our data do not exclude the possibility that increased SLC is a factor involved in the progression from microalbuminuria to clinical proteinuria, and on to frank nephropathy. However, this would be inconsistent with the data of Gall et al. [14]. If increased cation transport were an initiating factor for microalbuminuria in NIDDM, then our results would imply that erythrocyte SLC is an inadequate marker for the underlying defect.

Like us, Mattock et al. [20] found a relationship between microalbuminuria, on timed overnight urine samples, and blood pressure (mean of two clinic measurements) in Caucasian NIDDM subjects. In our study there were also relationships between AER and male gender (as shown by Mattock et al. [20]) and an increased duration of diabetes (not significant in the study of Mattock et al.). When we restricted our analysis to Caucasian subjects, similar relationships were seen between AER and blood pressure (but not SLC) as in the whole group. The observation that Afro-Caribbean subjects had lower SLC than Caucasian subjects, confirms a finding previously noted by other groups $[21,22]$.

The present study revealed a blunted nocturnal decline in heart rate in microalbuminuric subjects, but 
no blunting in the blood pressure decline at night. Several studies have examined circadian blood pressure and heart rate profiles in diabetic subjects. Studies in a heterogeneous group of diabetic subjects suggested that reduced circadian blood pressure and heart rate variations may result from autonomic neuropathy [23], and studies in subjects with NIDDM [24] also suggest that nephropathy is associated with reduced circadian blood pressure variation.

The present study found relationships between the duration of diabetes, $\mathrm{HbA}_{1}$, and AER, suggesting cumulative glycaemic exposure is also a possible determinant of increased AER in subjects with NIDDM, as is well established in IDDM [25-28].

From the methodological viewpoint, ambulatory blood pressure recording overcomes many problems of blood pressure classification from casual readings, including observer errors, and white-coat effects. One previous study suggested that ambulatory monitoring is superior to casual measurements in studying the relationship between blood pressure and AER in subjects with NIDDM [29], although in that study no association between microalbuminuria and hypertension was noted. In the present study, similar correlations were found between AER and the mean of three carefully recorded clinic measurements with a standard mercury sphygmomanometer, as were found with daytime ambulatory values (Table 2), and clinic blood pressure differentiated the normoalbuminuric and microalbuminuric groups as well as ambulatory recording (Table 4). This relationship was stronger than that found in previous studies in NIDDM subjects [3], in which clinic blood pressure correlated less strongly with AER $(r=0.12)$. Also, ambulatory blood pressure levels were consistently lower than casual levels, as has been observed previously [3].

The present study used timed overnight collections of urine to estimate AER. This approach, used by other investigators [20], gives results which correlate well with those from 24-h urine collections. The finding that increased AER is associated with increased blood pressure, is a conclusion reached in previous studies on non-diabetic subjects [30], in subjects with IDDM [25-27], and in subjects with NIDDM [20]. In the present study the relationships between blood pressure AER and SLC were present which ever value of AER was used to define microalbuminuria. Finally, although we initially selected subjects for study without dipstick-positive proteinuria, and not on the basis of AER less than $200 \mu \mathrm{g} \cdot \mathrm{min}^{-1}$, we suggest that the possible inclusion or exclusion of a few subjects with AER in the high microalbuminuric range would probably not have significantly affected the outcome.

The explanation for the apparent association between increased SLC and both essential hypertension and nephropathy in IDDM subjects, but not in
NIDDM is uncertain. It is possible either that our study had inadequate power, or that different mechanisms determine microalbuminuria in NIDDM and IDDM. Alternatively, erythrocyte SLC may be too insensitive a marker for underlying kinetic defects of sodium-hydrogen exchange [31].

In conclusion, this study suggests that microalbuminuric NIDDM subjects have higher blood pressure, longer duration of diabetes, worse glycaemic control and are more likely to be male, than normoalbuminuric subjects, without exhibiting any significant difference in SLC. These results suggests that an increased rate of SLC is not a marker for microalbuminuria in NIDDM. In contrast, however, hypertension and poor long-term glycaemic control could be important factors in the pathogenesis of microalbuminuria in these subjects.

\section{References}

1. Viberti GC, Hill RD, Jarrett RJ, Argyropoulos A, Mahmud U, Keen H (1982) Microalbuminuria as a predictor of clinical nephropathy in insulin-dependent diabetes mellitus. Lancet i: $1340-1342$

2. Mogensen CE, Chachati A, Christensen CK et al. (198586) Microalbuminuria. An early marker of renal involvement in diabetes. Uremia Incest 9: 85-95

3. Schmitz A, Vaeth M (1988) Microalbuminuria: a major risk factor in non-insulin dependent diabetes. A 10-year follow up study of 503 patients. Diabet Med 5: 126-134

4. Jarrett RJ, Viberti GC, Argyropoulos A, Hill RD, Mahmud U, Murrells TJ (1984) Microalbuminuria predicts mortality in non-insulin dependent diabetes. Diabet Med 1: 17-19

5. Mogensen CE (1984) Microalbuminuria predicts clinical proteinuria and early mortality in maturity-onset diabetes. N Engl J Med 310: 356-360

6. Canessa M, Ardagna N, Solomon HS, Connoly TM, Tosteson TC (1980) Increased sodium-lithium countertransport in red cells of patients with essential hypertension. $\mathrm{N}$ Engl J Med 302: 772-776

7. Mangili R, Bending JJ, Scott G, Li LK, Gupta A, Viberti GC (1988) Increased sodium-lithium countertransport activity in red cells of patients with insulin dependent diabetes and nephropathy. N Engl J Med 318: 146-150

8. Jones SL, Trevisan R, Tariq Tet al. (1990) Sodium-lithium countertransport in microalbuminuric insulin-dependent diabetic patients. Hypertension 15: 570-575

9. Krolewski AS, Canessa M, Warram JH, Laffel LMB, Christlieb AR, Knowler WC, Rand LI (1988) Predisposition to hypertension and susceptibility to renal disease in insulin-dependent diabetes mellitus. N Engl J Med 318: 140-145

10. Walker JD, Tariq T, Viberti G (1990) Sodium-lithium countertransport activity in red cells of patients with insulin dependent diabetes and nephropathy and their parents. BMJ 301: 635-638

11. Andersen AR, Christiansen JS, Andersen JK, Kreiner S, Deckert T (1983) Diabetic nephropathy in type 1 (insulindependent) diabetes: an epidemiological study. Diabetologia 25: 496-501

12. Herman WH, Prior DE, Yassine MD, Weder AB (1993) Nephropathy in NIDDM is associated with cellular markers for hypertension. Diabetes Care 16: 815-818 
13. Trevisan M, Vaccaro O, Laurenzi M et al. (1988) Hypertension, non-insulin dependent diabetes and intracellular sodium metabolism. Hypertension 11: 264-268

14. Gall MA, Rossing P, Jensen JS, Funder J, Parving $\mathrm{H}-\mathrm{H}$ (1991) Red cell $\mathrm{Na}^{+} / \mathrm{Li}^{+}$countertransport in non-insulin dependent diabetics with nephropathy. Kidney Int 39: 135140

15. Johnson BA, Sowers JR, Zemel PC, Luft FC, Zemel MB (1990) Increased sodium-lithium countertransport in black non-insulin-dependent diabetic hypertensives. Am J Hypertens 3: 563-565

16. Foyle W-J, Drury PL (1991) Reduction of $\mathrm{Na}^{+} / \mathrm{Li}^{+}$countertransport by physiological levels of insulin in vitro. $\mathbf{J}$ Hypertens 9: 713-717

17. Chesham J, Anderton SW, Kingdon CFM (1986) Rapid competitive enzymoimmunoassay for albumin in urine. Clin Chem 32: 669-671

18. Mohamed-Ali V, Yudkin JS (1992) An endpoint-amplified enzymoimmunoassay (IEMA) specific for human insulin. Clin Sci 82 [Suppl 27]: 4P (Abstract)

19. Sobey WJ, Beer SF, Carrington CA et al. (1989) Sensitive and specific two site immunoradiometric assays for human insulin, proinsulin, $64-65$ and $32-33$ split proinsulin. Biochem J 260: 535-541

20. Mattock MB, Morrish NJ, Viberti GC, Keen H, Fitzgerald AP, Jackson $G$ (1992) Prospective study of microalbuminuria as predictor of mortality in NIDDM. Diabetes 41 : 736-741

21. Trevisan M, Ostrow D, Cooper RS, Sempos C, Stamler J (1984) Sex and race differences in sodium-lithium countertransport and red cell sodium concentration. Am J Epidemiol 120: 537-541

22. Smith JB, Wade MB, Fineberg NS, Weinberger MH (1988) Influence of race, sex, and blood pressure on erythrocyte sodium transport in humans. Hypertension 12: 251-258
23. Hornung RS, Mahler RF, Raftery EB (1989) Ambulatory blood pressure and heart rate in diabetic patients: an assessment of autonomic function. Diabet Med 6: 579-585

24. Nakano S, Uchida K, Kigoshi T, Azukizawa S, Iwasaki R, Kaneko M, Morimoto S (1991) Circadian rhythm of blood pressure in normotensive NIDDM subjects. Its relationship to microvascular complications. Diabetes Care 14: $707-711$

25. Wiseman M, Viberti G, Mackintosh D, Jarret RJ, Keen H (1984) Glycaemia, arterial pressure and microalbuminuria in type 1 (insulin dependent) diabetes mellitus. Diabetologia 26: 401-405

26. Klein R, Klein BEK, Linton KLP, Moss SE (1992) Microalbuminuria in a population-based study of diabetes. Arch Intern Med 152: 153-158

27. Jones SL, Close CF, Mattock MB, Jarret RJ, Keen H, Viberti GC (1988) Plasma lipid and coagulation factor concentrations in insulin dependent diabetics with microalbuminuria. BMJ 298: 487-490

28. The Diabetes Control and Complications Trial Research Group (1993) The effect of intensive insulin treatment of diabetes on the development and progression of long term complications in insulin-dependent diabetes mellitus. $N$ Engl J Med 329: 977-986

29. Schmitz A, Pedersen MM, Hansen KW (1991) Blood pressure by $24-h$ ambulatory recordings in type 2 (non-insulin dependent) diabetics. Relationship to urinary albumin excretion. Diabete Metab 17: 301-307

30. Yudkin JS, Forrest RD, Jackson CA (1988) Microalbuminuria as predictor of vascular disease in non-diabetic subjects. Lancet ii: $530-533$

31. Canessa M, Morgan K, Goldszer R, Moore TJ, Spalvins A (1991) Kinetic abnormalities of the red blood cell sodiumproton exchange in hypertensive patients. Hypertension 17: 340-348 